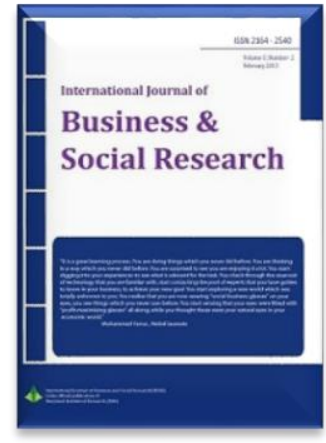

\title{
Decision-Making under Stress and Its Implications for Managerial Decision-Making: A Review of Literature
}

\author{
Kubilay Gok', Nuray Atsan²
}

\begin{abstract}
We examine the main theoretical models of decision making under stress and the effects of decision stress on decision making process to provide a deeper understanding of the decision making phenomenon. The literature review reveals that stress can have an impact on each stage of the decision-making process. The review also finds that decision makers could enhance their decisionmaking performance and prevent potential decision failures by means of adapting certain coping strategies.
\end{abstract}

Keywords: Decision-failures, decision making process, decision-making under stress, threat-rigidity.

JEL Codes: D03, L20, Moo

Available Online: 08-04-2016

This is an open access article under Creative Commons Attribution 4.0 License, 2016.

\subsection{INTRODUCTION}

Many decisions must be made under stressful conditions such as giving a speech or getting a risky surgery. An existing body of research evidence accumulated over the years shows that stress affects decision-making (Keinan et al., 1987; Lazarus, 2000; Starcke et al., 2008; Galvan and Rahdar, 2013). In contrast to a handful of studies showing positive effects, a great deal have revealed that stress affects decision-making in a negative way (Staal, 2004). Whilst it is possible to think and act more rationally under non-stress conditions, the research evidence indicates that decisions made under stressful conditions have a tendency to be much more irrational. Early work on this topic demonstrates that a person under stress makes unsystematic and hurried decisions and lacks a full consideration of all the options (Janis and Mann, 1977; Mather and Lighthall, 2012; Galvan and Rahdar, 2013). Stress can lead to a number of undesirable consequences, including a restriction or narrowing of attention, increased distraction, increases in reaction time and deficits in the person's working memory (Driskell and Salas, 1996).

Although the association between stress and normative and/or descriptive decision-making behavior represents an important dimension of human behavior, this has not been explored extensively in the

\footnotetext{
${ }^{1}$ Corresponding author. Department of Business Administration, Winona State University, USA. E-mail: kgok@hotmail.com.

2 Faculty of Economics and Administrative Sciences, Department of Business Administration, Akdeniz University, Antalya/TURKEY. E-mail: nurayatsan@gmail.com
} 
literature and the findings of the studies have been inconclusive (Kowalski and Vaught, 2003). There is also an interaction between stress and the stages of the decision making process. Decision-making is a process that is comprised of dynamic and interrelated steps rather than being a momentary and static development of action. According to Adler (1991) and Schramm-Nielsen (2001), the decision-making process is comprised of specific stages including the recognition of the problem, search of information, alternatives, assessment of alternatives, selection of an alternative, implementation, control and feedback. Stress can also have an impact on each stage of the decision-making process (Moschis, 2007). Nevertheless, studies that have investigated the effect of stress exposure on each stage of decision making process are rare when compared to the majority of the studies that have investigated structured decision making models. This review aims to fill this research gap.

Thus, the primary purpose of this study is to review the existing literature regarding decision-making under stress and propose strategies to prevent decisional failures that stem from perceived decision specific stress. In order to achieve this, the authors first introduced a review of the basic theoretical models to explain the decision-making behavior under stress. Next, a review of the effects of decisional stress on the decision-making process was presented. The paper concludes by offering suggestions in prevention and coping with decision failures that stem from decision-making under stress.

\subsection{THE BASIC THEORETICAL MODELS TO EXPLAIN DECISION-MAKING BEHAVIOR UNDER STRESS}

A review of literature on decision-making under stress reveals that the majority of the theories were derived on the basis of information generated by four different theoretical models. These models are as follows: conflict-theory of decision-making, threat-rigidity model of decision-making under stress, crisis model of decision-making under stress, and finally decision-making under time pressure model.

\subsection{CONFLICT-THEORY OF DECISION-MAKINC}

Janis and Mann (1977) treated decisional stress as a dependent variable such as perceived risk or loss, availability of promising alternatives, and time limits to process information and evaluate each alternative. Furthermore, they approached the concept of decision-making stress as a context and a problem-related phenomenon.

Their model speculates that decision-specific stress is caused by two sources. The first one involves the perceived level of threat or danger to the physical or material well-being of the decision-maker. The second source stems from decision context; it is related to the alternative choice under risk and the uncertainty and whether the decision-maker can remove themselves from the situation. In this case, the self-reputation of the decision-maker is at stake; his/her alternative choice determines whether he/she is a good or poor decision-maker. This explanation is an account of psychological and emotional expression for the decision-maker under stress.

Janis and Mann (1977) conclude that perceived stress in the decision-making process is a major cause of bad decisions and errors. However, they do not deny other influences of common causes. These include information overload, limitation of human information processing, group pressure, blinding prejudice, ignorance, organizational constraints, and bureaucratic politics. Janis (1982) cronicles five major behavioral patterns while trying to make decision-making under stress: These were as follows: (1) unconflicted adherence occurs when a decision-maker decides on continuing whatever s/he has been doing, ultimately ignoring the information about the risk of losses, (2) un-conflicted change happens when the decision-maker uncritically adopts whichever new course of action is most salient or most strongly recommended, (3) defensive avoidance take place when the decision-maker avoids conflict by procrastinating, shifting responsibility to someone else, or constructing wishful rationalizations and remaining selectively inattentive to relevant information, (4) hypervigilance takes place when a decisionmaker searches drastically for a way out of the dilemma and impulsively seizes upon a hastily contrived 
solution that seems to promise immediate relief, overlooking the full range of consequences of his/her choice because of intentional excitement and repetitive thinking. Janis, in its extremist form, refers to this behavioral pattern as panic, and finally (5) vigilance occurs when the decision-maker searches for relevant information, assimilates it in an unbiased manner, and appraises alternatives carefully before making a choice. Such approach is also referred to as the analytical decision-making behavior. This pattern considered optimal by many.

In an assessment of these five decision-making behavior patterns presented above, the first four behavior patterns are accepted as defective approaches. For instance, research evidence concerning hypervigilant behavior showed that stress tends to increase the number of task errors (Keinan, 1987; Baradell and Klein, 1993; Johnston et al., 1997; LeBlanc, 2009). Janis (1982) acknowledges the "vigilance" as the decision-making behavior pattern that leads to better quality decisions. However, when examining discussions on his theory, it has been often noted that under certain task conditions such as increased time pressure, adopting a less analytic decision-making strategy may be more adaptive. Furthermore, many authors emphasized that characteristics typical of hypervigilant decision-making including the narrowing of attention, filtering of information, the use of heuristics to speed information processing and rapid closure may represent an effectual response to naturalistic task demands (Johnston et al., 1997).

\subsection{THREAT-RIGIDITY MODEL}

The second approach to the study of decision-making under stress is the "Threat-Rigidity Effect" model by Staw et al. (1981). The threat-rigidity model is founded within a multi-level framework which outlines the decision-making under stress behavior at individual, group and organizational levels. The conceptual foundation for the individual level analysis originates from studies in anxiety, psychological arousal, disaster, and psychological stress research. If we review that literature closely, the individual analysis of threat rigidity approach is modelled on three levels: Firstly, there is the link between threat situations, psychological stress, and anxiety; Secondly, the nature of cognitive manifestations of stress, anxiety and arousal; The third one is the level between cognitive manifestations of stress anxiety, arousal and properties on individual behavior. The second level focuses on the group level analysis of the threatrigidity approach. The premise of the group level model is that the threat path to groups may either materialize from external or internal sources; these paths have unique implications on group processes. According to the model, if the threat is attributed to external sources, and if there is hope that the threat can be mediated, the group is expected to increase its internal cohesiveness and increase leadership support and pressure for group uniformity. The model foresees that with increased cohesiveness and pressure, the group has a tendency to restrict the information search, and to overlook the divergent opinion or alternatives from the group alternative evaluation stage. On the other hand, if the threat arises from deficiencies and dysfunctions of the internal operation of the group, it was predicted that cohesiveness and consensus will decrease. As a result, the group tends to seek additional information, and thus losing the central process in the group dynamics. The last level of analysis is the organizational level response and its relation to the external threat. The threat for the organization is described as a resource scarcity, competition or reduction in the size of the market. Influenced by an informational overload, there is perceived external threat to the communication channels. Organizational level policy may rely on prior knowledge and experience and on reducing the communication channel complexity which leads to a restriction of information processing. Thus, decision-making might lead to a centralization of authority through increased top-down information control; tendency to increase efficiency through cost-cutting or better allocation, or conservation of resources might also increase.

Staw et al. (1981) argued that the collapse of many organizations is related to their failures to adapt to the changing conditions caused by a stressful environment. Under threatening conditions, individuals, groups and organizations react by becoming more rigid and more controlling by centralizing decisionmaking, constricting the use of resources and limiting communication (Staw et al. 1981; Plotnick et al., 2009). As a result, they suggested a bilateral behavior pattern. First, the threat may result in the restriction of information processing, such as narrow-minded attention, a simplification of information 
codes, or a reduction in the number of channels used. Second, under existing threats, the power and influence mechanisms have a tendency to become more centralized and concentrated at the higher levels of organizations. They claim that rigidity in organizational processes makes them less flexible.

\subsection{THE CRISIS MODEL}

Hermann (1963) was one of the first to use a theoretical approach to decision-making under a crisis situation. This early perspective is important since it influences the future thinking in the study of decision-making under crisis (Billings et al., 1980). There are three elements to Hermann's model: a potential threat to an organization's main goal, a surprise from lack of a weariness concerning situations, and the existence of a short time span for decisions (Smart and Vertinsky, 1977; Billings et al., 1980).

Billings et al., (1980) stated that research that employs the crisis model does not produce consistent findings in support of the model elements. For example, they asserted that the element of surprise has had little empirical support; and should either be reformulated or removed from the model. Moreover, the empirical evidence did not support the time measures; perceived time pressure is a factor rather than a time limit in making a decision. The only variable that received consistent empirical support is the threat; they assume that smaller threats meant smaller probabilities of losses and/or less importance of goals.

In their new "Model of Crisis Perception", Billings et al., (1980) argue that the first steps of defining a situation as a crisis should invo1ve perceiving the event in the environment which triggers the crisis. They maintain that this triggering event must be perceived, attended to, and evaluated with respect to a fixed reference point and/or a standard. They argue that this defines what is inconsistent with the major decision-making literature; the first steps in most decision-making processes is problem searching which violates some criteria relating to individuals, groups, or organizations. The next step of this model is to evaluate the size of discrepancy, and to decide upon the perceived seriousness of the problem. The degree of perceived crisis is determined as a function of the interaction of three variables: perceived value of possible loss, probability of loss, and time pressure.

\subsection{THEORY OF DECISION-MAKING UNDER TIME PRESSURE}

Acute stress has a rapid and time dependent effect on decision making (Pabst et al., 2013). Individuals often have to make decisions under strict deadlines. This may be a daunting task that creates stress and cognitive strain. From this point of view, "theory of decision-making under time pressure" developed by Bronner (1982) has become a major theory of decision making under stress. Bronner (1982) determines three elements of time pressure: decision time, sensitivity, and problem intensity. First, the decisionmaker must understand that time is an obligatory part of problem-solving; any violation would lead to a reduction in decision effectiveness. Second, differences in the cognitive structure of people will predict differing degrees of sensitivity to time pressure exposure. Third, Bronner (1982) states that problem intensity reflects problem evaluation from the decision-maker's perspective; it reflects the subjective assessment of the situation. As the scope of the decision-making problem increases, the intensity of the problem also increases. As well as these three elements, he notes that time pressure leads to a limitation of interaction and coordination among the decision-making units. Using a gambling paradigm in their examination of decision strategies, Ben Zur and Breznitz (1981) discover that decision makers under time pressure have a tendency to make lower risk choices and spend more time viewing negative dimensions of the decision. Rothstein (1986) also examined decision making under time pressure and found that subjects were able to implement sound decision policies, but their behavior becomes more erratic than when time for their decisions was not limited.

Several researchers suggest that under time constraints, decision makers try to boost up the decisionmaking process and if it is not possible then shift to the simplest strategy (Wright, 1974; Raaijmakers, 1990; Edland and Svenson, 1993). Miller (1960) hypothesized that people use filtration, acceleration and avoidance strategies to handle time pressure. When using the filtration strategy, the decision maker processes the important information first and then prioritise information until time runs out. During 
acceleration, the decision- maker processes the information at a faster rate which it is possible to lead to misinterpretation of the information. The decision-maker attempts to avoid the situation during the avoidance strategy. In a study examining how decision makers adapt to time constraints, Payne et al. (1988) found similar findings. According to their study, decision makers were able to adapt to time pressure by selectively filtering information, using simpler heuristics and accelerating information processing to reach a timely decision. These strategies have much in common to coping strategies Janis and Mann (1977) discussed in their model.

In brief, research suggests three major ways in which people respond to decision problems under time pressure. First, people accelerate their processing. Second, processing tends to be more selective under time stress focusing on more important and/or negative information about alternatives. Third, decision strategies may shift as a function of increased time pressure (Payne et al., 1996).

\subsection{EFFECTS OF DECISION STRESS ON THE DECISION-MAKING PROCESS BEHAVIOR}

While a great majority of the research studies on decision-making has concentrates on the decision outcome itself, the decision-making process is also an important aspect of decision making. Decisionmaking process is multi-faceted which concerns with a series of steps, namely recognition of problems or objectives, generating alternative courses of action, evaluating and/or ranking possible alternatives of action, making a choice from among them and implementing the selected course of action (Kowalski and Vaught, 2003). There is no question that stress can impact each stage of the decision-making process (Moschis, 2007). However, three aspects of the decision making process seem to be particularly susceptible to the effects of decision related stress. These are (a) the gathering and judgment of information, (b) the generation of options and (c) the judgment and comparison of options (Raaijmakers, 1990). Understanding the decision process under stressful conditions can provide additional insight into the field of decision-making and it is possible to raise an awareness of the potential failure sources for managers when making decisions. Therefore, this section analyzes the association between stressors and decision making process.

\subsection{ON ALTERNATIVE GENERATION AND ASSESSMENT}

The implication of decision stress is directly related to the generation of alternatives and its consequences. Mandler (1982) identified that when people are under stress, the range of alternatives that are available to them and the dimensions of each of those decisions that are considered during the decision making process are significantly restricted, when compared with normal conditions. Keinan (1987) also reported similar findings. He examined the performance on a multiple choice analogies test to assess the range of alternatives considered by subjects prior to making a decision. Keinan (1987) employed the threat of electric shock as his stress manipulation. He observed that when individuals feel threatened they are inclined to abandon their previously organized and systematic scanning patterns. This results in a failure to consider as many alternatives as possible. Furthermore, those who examined the alternatives were less systematic in their evaluation of alternatives, reducing the quality of their decisions that they made (Staal, 2004). Keinan (1987) noted that decision stress can influence decisionmaking in three ways: premature closure, nonsystematic scanning and temporal narrowing.

Premature closure refers to a situation where decisions are given before all available alternatives are formulated and deliberated and assessed concerning their potential to generate a potential solution to a perceived problem or crisis. Several authors note that a high level of decision stress narrows the span of cognitive processes as well (Smart and Vertinsky, 1977; Janis, 1982; Keinan et al., 1987). For instance, Hamilton (1982) finds that decision specific stress impairs cognitive functions of decision-makers such as cognitive flexibility, reasoning, concentration, and the ability to retrieve from memory. Furthermore, research suggests that stressed individuals devote part of their conscious attentional capacity to the stress and consequently are left with insufficient capacity to deal with the decision. This could result in an incomplete consideration of all the viable alternative choices, which is considered as one of the 
defense mechanisms to prevent information overload. Disorganized and incomplete scanning of alternatives may result in evading from an undesirable situation as soon as possible (Mandler 1982). Additionally, experimental studies suggest that stress potentially intensifies behavioral biases in decisionmaking by inducing more conservative choices for those who are generally risk averse and riskier choices for those who tend to be risk seekers (Porcelli and Delgado, 2009; Young et al., 2012; Galvan and Rahdar, 2013).

Nonsystematic Scanning refers to the disorganized and nonsystematic consideration of decision alternatives (Keinan 1987). Staw et al. (1981) conclude that under hypervigilant conditions, restriction of information processing occurs as a result of decreased information exchange. Decision-makers fail to exhibit enough sensitivity to the key aspects of the problem. A similar, but more comprehensive analysis of this process, was made by Janis and Mann (1977). They state that the failure in the systematic and organized analysis of decision-making alternatives originates from when a decision-maker does not meet the seven criteria of effective decision-making. These criteria are as follows: (1) to develop a broad range of alternatives, (2) to see the values of each objective and to evaluate their consequences, (3) to weigh the negative and positive consequences of each alternative, (4) to search for more information, (5) to consider any more facts or other expert judgments, (6) to reexamine the positive or negative consequences of all alternatives, (7) to develop or make a detailed plan for implementing or executing the chosen course of action.

The Janis and Mann (1977) model of decision-making was supported by several studies (Keinan 1987; Baradell and Klein, 1993). However, Johnston et al., (1997) criticizes these studies on the ground that settings in real-world decision-making differ quite considerably from the laboratory tasks. They stress that naturalistic decision tasks share several key characteristics prevalent in many real-world decision environments such as time pressure, and conflicting nature of the information available. In their study, Johnston et al., (1997) show that participants who used a hypervigilant decision-making strategy perform better than those who use a vigilant strategy, contradicting what was advocated by earlier researchers.

Temporal Narrowing is another implication of decision stress. This occurs when devoting a very short period of time to the development of alternatives. Janis (1982) asserts that a decision-maker under stress chooses a solution hastily but such solution may provide immediate relief from decision stress. Research also indicates that individuals respond to stress by a restriction of or narrowing attentional focus (Driskell et al., 1999). Under stressful conditions, the cognitive system becomes overloaded, decreasing a person's attentional resources. In other words, stress depletes one's available resources (Chajut and Algom, 2003). As stress increases and attention becomes more selective, there is a growing tendency to exclude information that is relevant to the task at hand. There is also some evidence that the reduction of attentional resources under stress may result in a decreased ability to filter out irrelevant information from relevant information. Hence stress can also lead to increased distractibility of the individual (LeBlanc, 2009).

\subsection{ON INFORMATION USE AND EVALUATION}

The second implication of the decision specific stress is about information use and evaluation. For instance, Ozel (2001) examined how fire fighters process environmental information used for the decision to exit a fire. Under time pressure and the threat of fire, Ozel (2001) asserted that when slightly "stressed" one's ability to determine the best time to exit was likely to be enhanced, while under high levels of stress there would probably be a restriction in the range of cues attended to and a distortion of information processing. He suggests that the result was likely to be a decrement in performance (Staal, 2004). Smart and Vertinsky (1977) argue that changes in communication channels during crisis situations distort the flow of information in the organization. The communication channels can be reduced, and flow of information can be controlled by a centralized authority. Overload of information and the need to respond quickly force decision-makers to use fewer channels, therefore, reducing their information sources. Under high time pressure and decision stress, organizations and individuals can adapt some mechanisms to handle this problem and reduce their decision specific stress. They may adopt a simpler 
mode of information processing in which alternatives are not fully explored, and certain important cues are used to determine the decision. The focus of attention shrinks and the individual focuses just on critical issues and elements (Hwang, 1994; Kowalski and Vaught, 2003). Ben Zur and Breznitz (1981) say that decision-making under stress also may lead to strategies such as filtering information, accelerating the processing of information evaluation, and the avoidance from the problem. Smart and Vertinsky (1977) noted that these strategies distort the information. They advise that these dysfunctions may possibly be reversed through the careful planning of arrangements. The analysis of empirical research reveals that the amount of information searched and the pattern of this search are the significant elements of whether having a good information system or not.

\subsection{ON CHOICE FROM AMONG ALTERNATIVES}

The process of choosing from among alternatives itself can generate some degree of psychological stress. It may become more challenging to make a choice from a variable of available alternatives under the conditions of time pressure, uncertainty, threat, crisis and risk. Klein observes that decision-makers in natural settings often use their experience to identify meaningful data and generate reasonable options, they use simplifying heuristics to select a course of action and then implement the first workable solution (cited in Johnston et al., 1997: 615). Janis and Mann (1977) claim that hypervigilant decisionmaking under stress not only leads to deterioration in thinking, judgment, perception and search of information but also results in impulsive choices. Experimental studies suggest that stress potentially intensifies behavioral biases in decision making by inducing more conservative choices for those who are generally risk averse and riskier choices for those who tend to be risk takers (Porcelli and Delgado, 2009; Galvan and Rahdar, 2013). Recent research evidence also shows that when people make decisions under stress, they tend to pay more attention to positive information and discount negative information (Mather and Lighthall, 2012). Their findings show that "stress seems to help people learn from positive feedback and impairs their learning from negative feedback". This means when people make a difficult decision under stress, they may pay more attention to the upsides of the alternatives they're considering while giving less attention to the downsides of the alternatives they consider as a potential solution for their problems.

This review of extant research shows that downplaying the negative implications of a decision outcome could lead to poor choices. So, what can managers do to prevent against making poor choices in their decisions. With this in mind, in the final section of the review paper, a list of potential strategies that managers can use to cope with decision stress and prevent decision failures is offered.

\subsection{HOW TO AVOID POTENTIAL DECISION FAILURES}

Though many decisions must be made under stress and many decision situations elicit stress responses themselves (Starcke and Brand, 2012), decision makers could enhance their decision-making performance and protect against potential decision failures (Whyte, 1991) by means of adapting certain coping strategies.

1. Use Balance sheet exercise. Janis (1982) suggests that decision makers can foster vigilance by means of using the "balance sheet" exercise. This is a pre-decision process that asks the decision-maker to confront and answer the questions about the potential risks and gains not previously contemplated. Janis (1982) asserts that without an application of a systematic approach, even the most motivated and alert person may overlook some vital dimensions of the problem being considered. The "balance sheet" approach is useful in the sense that it enables a decision-maker thoroughly to evaluate his or her alternatives and consequences.

2. Use check lists. Kruglanski (1986) suggests that potential decision failures could be prevented by means of a preparing a check-list for all aspects of the alternatives, and before selecting the "best" alternative, these aspects should be compared against to the criteria check-list.

3. Heighten the fear of failure. Kruglanski (1986) advocates that inserting several reminders into the decision-making process may be help to raise the fear of failure. As an example, a few 
people may be assigned to remind the decision makers of the negative consequences of their course of action. Kruglanski (1986) also claims that making people aware of the processes, which often lead to biased judgments, would increase their ability to avoid these biases.

4. Analyze the sources of decision-making stress. Several authors, such as Smart and Vertinsky, (1977), and Billings et al., (1980) suggest that one of the significant sources of decision-making stress is the necessity of making a choice within a fixed time period. However, they address that within this fixed period, the information overload accelerates the stress felt by decisionmakers. The processing too much information possibly could lead to less rational behaviors on the part of the decision-makers. Consequently, the possibility to distort the information and ignore the major aspects of the problem increases. Therefore, keeping the information load at a standard pace can have implications to reduce the level of cognitive and emotional stress felt by the decision-maker.

5. Use decision support systems whenever feasible. Using decision-support systems is a powerful means to combine human judgment and the power of computer technology to improve the effectiveness and quality of decision-making outcomes. It has been shown that decision support systems could be specifically designed to mitigate the negative effects of stress on human decision-making (Phillips-Wren and Adya, 2009).

6. Order task priorities. Research findings suggest that providing training on how to order task priorities and use efficient search strategies is an alternative way to enhance the decision quality and prevent potential decision failures while making decisions under stress (Mann and Tan, 1993). Several cognitive behavioral stress-coping training programs have been shown to be effective in combatting decision related stress (Cannon-Bowers and Salas, 1998). The main aim is to prevent panic in a stressful situation and to achieve the best possible cognitive processing and decision outcome. Useem et al. (2005) suggest providing cases, exercises and simulations in business schools to enhance future leaders and managers' situational awareness and clear-mindedness under stress.

\subsection{CONCLUSION}

The main purpose of this study was to gain an insight into the relationship between decision-making and stress. This review of extant research suggests that decision making under stress results in distortions in the information gathering, alternative generation, the assessment of available choices, and finally in the stage of making a choice from among alternatives available to the decision-maker. By highlighting sources of decision-making stress and its implications for decision-making behavior, the authors hope that organizations and their managers can adopt certain strategies to scan the information and find alternatives without panic. The use of principles suggested by the different models may also help managers to discover their weaknesses in their decision-making behavior more clearly. The comparison of the criteria can serve as a check-balance system against non-rational and emotional reactions in the organizations. The other implication for the practice of management is that since the managers can commit themselves to any course of action, involving more people in the decision making and consulting the expert judgment can assist managers to better evaluate the negative and positive consequences of their actions.

There are many points for future research to supplement and support the findings. A range of factors such as personality, cognitive capabilities, emotional and physiological states may have inputs in the decision making behaviors under stress and thus, should be examined systematically. Additionally, future research may focus on cross cultural differences in decision making process and compare the stressors, individual and team decision making behaviors under stressful conditions in different nations. 


\section{REFERENCES}

Adler, N.J. (1991) International Dimensions of Organizational Behavior, Kent Publishing Co., Boston.

Baradell, J. and Klein, K.W. (1993). The relationship of life stress and body consciousness to hypervigilant decision making, Journal of Personality and Social Psychology, 64, 267-273.

Ben Zur, H. and Breznitz, S. J. (1981). The effect of time pressure on risky choice behavior, Acta Psychologica, 47(2), 89-107.

Billings, R. S., Milburn T.W. \& Schaalman M.L.(1980). A model of crisis perception: A theoretical and empirical analysis, Administrative Science Quarterly, 25(2), 300-316.

Bronner, R. (1982). Decision making under time pressure. Toronto: Lexington Books.

Cannon-Bowers, J.A. \& Salas, E. (Eds.) (1998). Making decisions under stress: Implications for individual and team training. Washington, D.C.: APA Books.

Chajut, E. \& Algom, D. (2003). Selective Attention Improves Under stress: Implications for Theories of Social Cognition, Journal of Personality and Social Psychology, 85(2), 231-248.

Driskell, J. E., \& Salas, E. (1996), Stress and human performance. Mahwah, NJ: L. Erlbaum.

Driskell, J.E., Salas, E. \& Johnston, J. (1999). Does Stress Lead to a Loss of Team Perspective? Group Dynamics: Theory, Research, and Practice, 3(4), 291-302.

Edland, A., \& Svenson, O. (1993). Judgment and decision making under time pressure: Studies and findings, in O. Svenson \& A. J. Maule (Eds.), Time pressure and stress in human judgment and decision making, New York: Plenum, 27-39.

Galván, A. \& Rahdar, A.(2013). The neurobiological effects of stress on adolescent decision making, Neuroscience, 249, 223-243.

Hamilton, V. (1982). Cognition and stress: an information processing model, in: L. Goldberger and S. Breznitz (eds.), Handbook of stress: theoretical and clinical aspects. New York: Free Press., 105-120.

Hermann, C.F. (1963). Some consequences of crisis which limit the viability of organizations, Administrative Science Quarterly, 8, 61-82.

Hwang, M. (1994). Decision making under time pressure: a model for information system Research, Information \& Management, 27, 197-203.

Janis, I.L. \& Mann, L. (1977). Decision making: A psychological analysis of conflict, choice, and commitment. New York: The Free Press.

Janis, I. L. (1982). Groupthink: Psychological studies of policy decisions and fiascoes. Boston: Houghton Mifflin.

Johnston, J., Driskell, J. E., \& Salas, E. (1997). Vigilant and hypervigilant decision making, Journal of Applied Psychology, 82, 614-622.

Keinan, G. (1987). Decision Making Under Stress: Scanning of Alternatives Under Controllable and Uncontrollable Threats, Journal of Personality and Social Psychology, 52(3), 639-644.

Keinan, G., Friedland, N., \& Ben-Porath, Y. (1987). Decision making under stress: Scanning of alternatives under physical threat, Acta Psychologica, 64, 219-228.

Kowalski, K.M. and Vaught, C. (2003). Judgement and decision making under stress: An overview for emergency managers, International Journal of Emergency Management, 1(3), 278-289.

Kruglanski, A. W. (1986). Freeze-think and the Challenger, Psychology Today, August, 48-49.

Lazarus, R. S. (2000). Toward Better Research on Stress and Coping, American Psychologist, 55(6), 66573.

LeBlanc, V.R. (2009). The Effects of Acute Stress on Performance: Implications for Health Professions Education, Academic Medicine, 84(10), 25-33.

Mandler, G. (1982). Stress and thought processes, in L. Goldberger \& S. Breznitz (Eds.), Handbook of stress: Theoretical and clinical aspects. New York: The Free Press.

Mann, L. \& Tan, C. (1993). The Hassled Decision Maker: The Effects of Perceived Time Pressure on Information Processing in Decision Making, Australian Journal of Management, 18(2), 197-210.

Mather M. \& Lighthall, N.R. (2012). Both Risk and Reward are Processed Differently in Decisions Made Under Stress, Curr Dir Psychol Sci, 21(2), 36-41.

Miller, J.G., 1960. Information input overload and psychopathology. American Journal of Psychiatry $116,695-704$ 
Moschis, G.P. (2007). Stress and consumer behavior, Journal of the Academy of Marketing Science, 35(3), 430-444.

Ozel, F. (2001). Time pressure and stress as a factor during emergency egress, Safety Science, 38, 95-107.

Pabst, S., Brand, M., \& Wolf, O.T. (2013). Stress and decision making: a few minutes make all the difference, Behavioral Brain Research, 250, 39-45.

Payne, J.W., Bettman, J.R. \& Johnson, E.J. (1988). Adaptive strategy selection in decision Making, Journal of Experimental Psychology: Learning, Memory \& Cognition, 14, 534-552.

Payne, J.W., Bettman, J.R. \& Luce, M.F. (1996). When time is money: Decision Behavior under Opportunity-Cost Time Pressure, Organizational Behavior and Human Decision Processes, 66 (2), 131152.

Phillips-Wren, G. \& Adya, M. (2009). Risky Decisions and Decision Support - Does Stress Make a Difference?, Proceedings of JAIS Theory Development Workshop Sprouts: Working Papers on Information Systems, 9 (55). http://sprouts.aisnet.org/9-55

Plotnick, L., Turoff, M., \& Van Den Eede, G. (2009). Reexamining Threat Rigidity: Implications for Design, Hawaii International Conference on System Sciences (HICSS) Waikoloa, Big Island, Hawaii.

Porcelli, A.J. \& Delgrado, M.R. (2009). Acute Stress Modulates Risk Taking in Financial Decision Making, Psychological Science, 20(13), 278-283.

Raaijmakers, J.G.W. (1990). Decision making under mental and physical stress, Faculty Report, Downloaded from UvA-DARE, the institutional repository of the University of Amsterdam (UvA). http://hdl.handle.net/11245/2.34113, 20.08.2014.

Rothstein, H. G. (1986). The effects of time pressure on judgment in multiple cue probability learning. Organizational Behavior and Human Decision Processes, 37, 83-92.

Shramm-Nielsen, J.,(2001) "Cultural dimensions of decision making: Denmark and France compared", Journal of Managerial Psychology, 16(6): 404-423.

Smart, C., \& Vertinsky, I. (1977). Designs for crisis decision units, Administrative Science Quarterly, 22, 640657.

Staal, M.A. (2004). Stress, Cognition and Human Performance: A Literature Review and Conceptual Framework, Ames Research Renter, Research http://humanfactors.arc.nasa.gov/flightcognition/Publications/IH_054_Staal.pdf. , 15.09.2014.

Starcke, K., Wolf, O. T., Markowitsch, H. J., \& Brand, M. (2008). Anticipatory stress influences decision making under explicit risk conditions, Behavioral Neuroscience, 122, 1352-1360.

Starcke, K. \& Brand, M. (2012). Decision making under stress: A selective review, Neuroscience and Biobehavioral Review, 36(1), 1228-1248.

Staw, B. M., Sandelands, L.E., \& Dutton, J.E. (1981). Threat-rigidity effects in organizational behavior: A multi-level analysis, Administrative Science Quarterly, 26, $501-524$.

Useem, M., Cook, J. \& Sutton, L. (2005). Developing Leaders for Decision Making Under Duress: Wildland Firefighters in the South Canyon Fire and Its Aftermath, Academy of Management Learning and Education, 4, 461- 485.

Whyte, G. (1991). Diffusion of responsibility: Effects on the escalation tendency, Journal of Applied Psychology, 76 (June), 408-415.

Wright, P. (1974). The harassed decision maker: Time pressures, distractions, and the use of evidence, Journal of Applied Psychology, 59, 555-561.

Young, D.L., Goodie, E.S., Hall D.B., \& Wu, E. (2012). Decision Making under time pressure modelled in a prospect theory framework, Organizational Behavior and Human Decision Processes, 118, 179-188. 